\title{
Article \\ Maximizing the Standing Skyline Log Load Using a Variable Length Tagline
}

\author{
John Sessions *, Kevin Lyons and Jeff Wimer \\ Department of Forest Engineering, Resources, and Management, Oregon State University, \\ Corvallis, OR 97331, USA; kevin.lyons@oregonstate.edu (K.L.); jeff.wimer@oregonstate.edu (J.W.) \\ * Correspondence: john.sessions@oregonstate.edu
}

\section{check for}

updates

Citation: Sessions, J.; Lyons, K.; Wimer, J. Maximizing the Standing Skyline Log Load Using a Variable Length Tagline. Forests 2021, 12, 927. https://doi.org/10.3390/f12070927

Academic Editor: Angela Lo Monaco

Received: 19 May 2021

Accepted: 12 July 2021

Published: 15 July 2021

Publisher's Note: MDPI stays neutral with regard to jurisdictional claims in published maps and institutional affiliations.

Copyright: (c) 2021 by the authors. Licensee MDPI, Basel, Switzerland. This article is an open access article distributed under the terms and conditions of the Creative Commons Attribution (CC BY) license (https:// creativecommons.org/licenses/by/ $4.0 /)$.

\begin{abstract}
The standing skyline continues to be a common cable logging configuration. In payload analysis it is usually assumed that the tagline (line connecting the logs to the carriage) length is held constant while yarding a turn up the skyline corridor. We show this assumption severely limits the skyline load-carrying capacity for skylines operating with partial suspension. We suggest that smart carriage technology could markedly increase the log load capacity through the use of a variable length tagline, and thus logging productivity. A methodology for estimating the log load capacity for a standing skyline with variable tagline length is presented. We illustrate that increases of 30-40 percent in log load are possible with a variable length tagline.
\end{abstract}

Keywords: cable analysis; payload analysis; steep slope logging; logging productivity; tethered logging

\section{Introduction}

The standing skyline continues to be a common cable-logging configuration and when yarding uphill it employs a skyline and mainline, and does not require a haulback (Figure 1). When using a standing skyline, the unstretched length of the skyline is not changed while yarding a turn. The harvest planning problem is to develop a plan that safely maximizes the system productivity. Often this is achieved by minimizing the number of log loads needed to yard the skyline corridor. Minimizing the number of log loads requires carrying the maximum permissible log load each trip which implies maximizing the load that can be brought to roadside from each terrain point either fully suspended or partially suspended depending upon the design requirements.

Mathematical formulations and algorithms for determining the maximum log load that can be carried for a standing skyline system under full and partial suspension for uphill and downhill yarding for single spans have been presented by [1,2] and others, with particular emphasis on load path analysis as the carriage moves along the skyline with a log load. More recent formulations focusing on full suspension and utilizing intermediate supports have been presented by [3-6]. There has also been some interest in the doublehitch system to take advantage of a reduced load clearance by hooking logs on both ends to fully suspend the log [7].

The tagline is the cable that connects the chokers to the carriage and that passes the vertical and horizontal forces of the log load to the skyline and mainline (Figure 1). A common specification in most standing skyline operations, and in all skyline analysis formulations that we could identify in the literature, is that the tagline is of fixed length while yarding a load of logs up the corridor. We will show later that the fixed tagline length in a standing skyline system is a severe constraint to the log loads that can be brought to the landing. The effectiveness of partial suspension in increasing permissible log loads over full suspension is by reducing the vertical force that the skyline and mainline must support. The effectiveness of reducing the vertical force the skyline and mainline must 
support has been recognized by a number of authors in a variety of functional forms. One of the earliest is by [8] who expressed this ratio

$$
W_{V} / W=\left[1-\frac{\cos \varphi-\sin \varphi \tan \beta}{\left(\frac{L L}{\varepsilon}\right)(1+\mu \tan \beta)}(\cos \varphi-\mu \sin \varphi)\right]
$$

as $W_{V}$, the vertical force passed to the skyline and mainline, $W$ as the log load, $\varphi$ as the ground slope under the dragging end of the $\log , \beta$ as the log-to-ground angle, LL as the log length, $\varepsilon$ as the distance from the point of log attachment to the center of mass of the log load, and $u$ as the coefficient of log-to-ground friction (Equation (1)). As the sum of $(\varphi+\beta)$ approaches 90 degrees, the log is fully suspended and the skyline and mainline support the entire weight of the log load (Figure 2). We invert Carson's equation in Figure 2 to show the effectiveness of partial suspension in increasing allowable log load per newton of vertical force passed to the skyline and mainline. For example, on a $40 \%$ slope with a log-to-ground angle of 5 degrees, for each newton of vertical force passed to the skyline and mainline, we can have a log load of 1.33 newtons, a 33\% increase over full suspension. At a 45 degree log-to-ground angle, the advantage falls to $10 \%$.

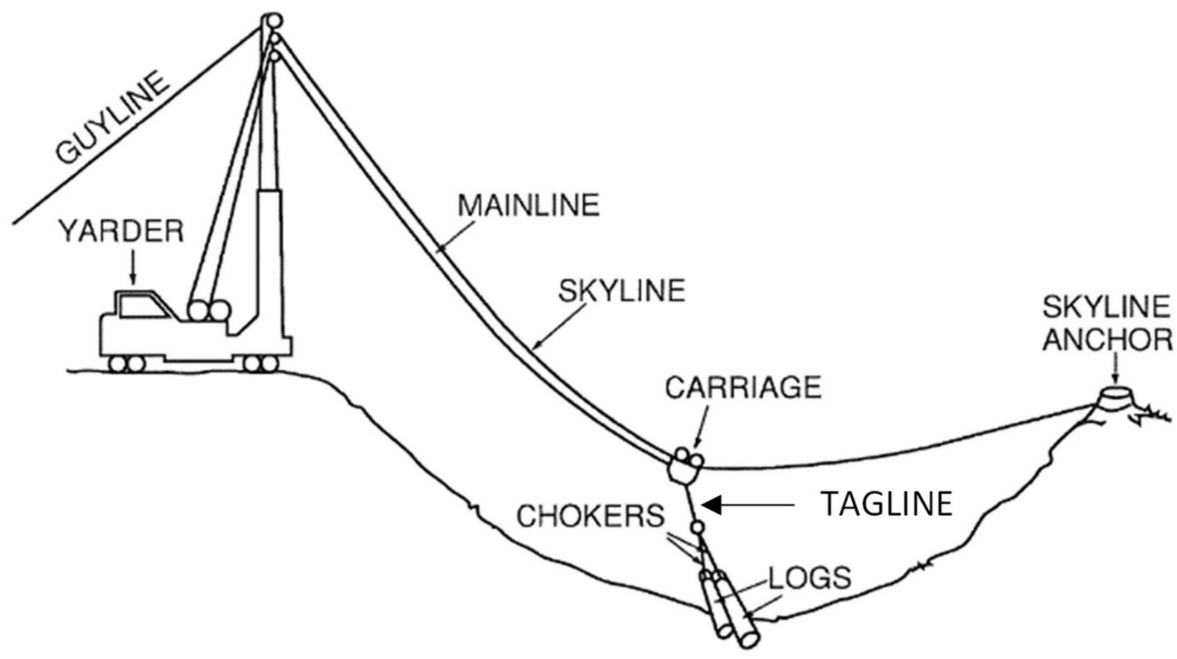

Figure 1. Uphill yarding with a standing skyline cable harvesting system.

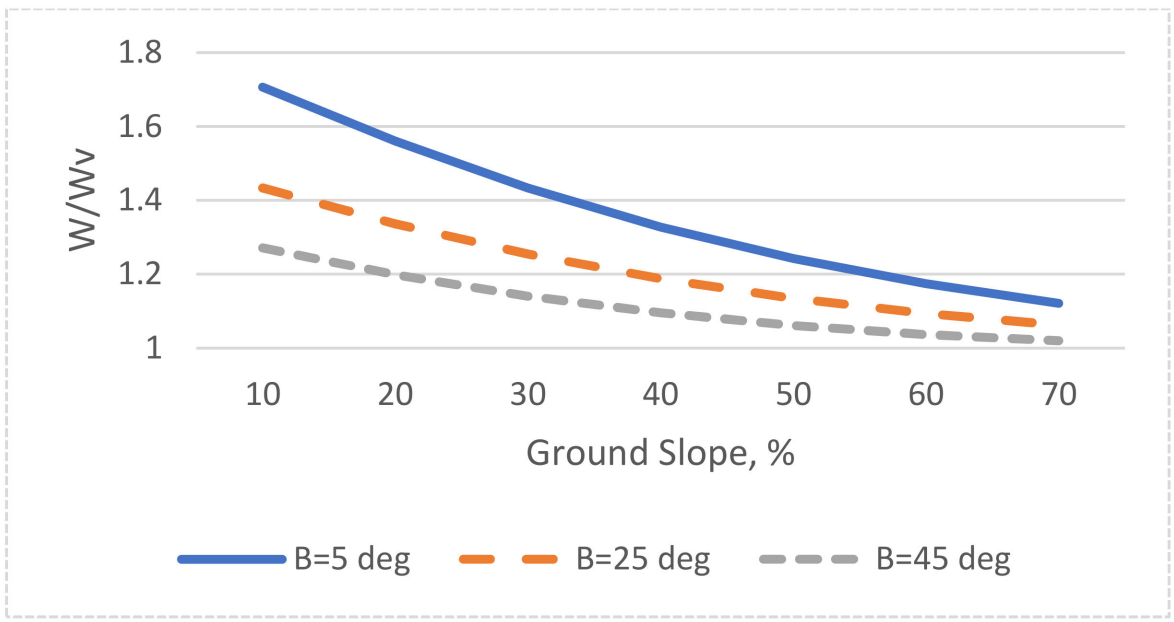

Figure 2. Ratio of log load to vertical force passed to skyline and mainline as a function of ground slope for three log-to-ground angles for $L L=12.2 \mathrm{~m}, \varepsilon=6.1 \mathrm{~m}, \mathrm{u}=0.9$. 
All other things being equal, the smaller the log-to-ground angle, the more of the $\log$ weight is supported by the ground and the larger the possible log load for a specified maximum skyline tension. The minimum log-to-ground angle is normally determined by the front-end log clearance needed to clear the obstructions in the skyline corridor. In live and running skylines, the fixed tagline length is less of an issue compared to standing skylines, as the skyline can be raised or lowered to take advantage of the terrain in boosting the skyline payload ability by adjusting the skyline length so that the ground supports more of the log weight. For the standing skyline, it is not possible with a fixed tagline length to maintain a constant front end log clearance because the skyline has a fixed unstretched length.

Achieving the maximum log load has always been an important factor in cable-logging productivity. Although many thought the days of large log loads were a thing of the past, the rapid introduction of tethered logging (Figure 3) has brought mechanized felling and bunching to steep slopes [9]. Building tree bunches in the skyline corridor of 45 to $90 \mathrm{kN}$ are now possible.

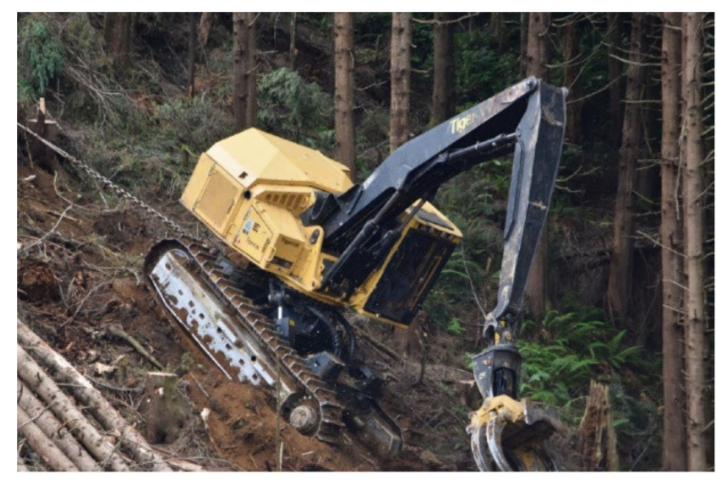

Figure 3. Tethered feller-buncher on a steep slope.

When considering the effect of tagline tension and direction on the capacity of a skyline system it is necessary to search all cable segments for limiting tensions. Both the horizontal and vertical component of the tagline tension will affect the other supporting cables in the system. At higher log angles the effect of the horizontal component of the tagline tension on the ratio of log load divided by vertical component of the tagline tension is small; however, the effect becomes larger at low log angles when the ground is supporting more of the weight and the resulting friction force is larger. Thus, this paper will examine in a full cable system analysis, the effect of reducing the log angle on the payload that can be moved by a standing skyline while varying the tagline length. In this manuscript we introduce an algorithm for establishing the lower bound on the maximum log load that can be brought to the landing with a variable length tagline from each terrain point within yarding limits. We begin with a description of the mathematical model for identifying the maximum log load that can be yarded using the variable length tagline in the context of minimizing the number of log loads to yard the harvest corridor. We then solve the problem heuristically and compare the results to a standing skyline using a fixed length tagline.

\section{Methods}

\subsection{Mathematical Formulation}

Our objective is to minimize the number of log loads to yard the skyline corridor. We assume this is met by maximizing the log load that can be brought from each terrain point to the landing, and by extension, maximizing the sum of the maximum log loads over all the terrain points within yarding limits on the skyline corridor without exceeding the maximum allowable tension in the skyline or mainline at any point. The tagline length is allowed to vary in order to maintain a fixed front end log clearance. We use the rigid link model formulation by [10] which has been shown to yield results very close to the catenary formulation when the cable is at relatively high tension. The rigid link model assumes 
the weight of the cable segment can be estimated by its straight line distance multiplied by the unit weight of the cable. Other segment model formulations could be used, such as the hybrid rigid link model [11] or the catenary [12]. We omit dynamic forces. The static force equilibrium model has been compared to empirical measurements by $[13,14]$. Studying three different harvesting sites in the Italian Alps that used standing skylines, researchers found close agreement between the static force model described here for both fixed and partial suspension compared to empirical measurements. The static force model software used by [13], SkylineXL [15], incorporated the methodology and equations from LOGGERPC [16]. Similarly, [4] found good agreement between predicted and observed performance for a standing skyline using static equilibrium.

The line segments and force components at the carriage and log are shown in Figure 4. We assume the carriage moves along an elliptical path such that the stretched length of the skyline remains the same at any terrain point [11]. The distance from the top of the yarder headspar to the carriage at terrain point $i$ is given by Equation (7). The maximum load that can be transported to the landing from each terrain point is limited by the maximum log load that can be moved at terrain point $i$, conditioned by the maximum load capacity at all preceding points to the landing. Equation (3) requires that the $\log \operatorname{load} W_{i}$ at terrain point $i$ can reach the landing without exceeding the maximum log loads permissible at preceding points, $j$, between terrain point $i$ and the landing. Equations (4)-(18) establish the geometry and Equations (19)-(31) maintain the static force equilibrium at each point within permissible line tensions.

The objective function is:

$$
\text { Maximize } \sum \mathrm{W}_{\mathrm{i}}, i=1 \ldots \mathrm{n}
$$

Subject to:

$$
\begin{aligned}
& W_{i}<=W_{j}, \mathrm{j}=1 . . \mathrm{i}-1, i=2 \ldots \mathrm{n} \\
& S_{i+1}=S_{i}, i=1 \ldots \mathrm{n}-1 \\
& S_{i}=L_{1 i}+L_{2 i}, i=1 \ldots \mathrm{n} \\
& d_{1 i}=\left(x_{t}-x_{i}\right), i=1 \ldots \mathrm{n} \\
& h_{1 i}=\frac{\left(S_{i}^{2}+d_{1 i}^{2}-\left(X-d_{1 i}\right)^{2}-Y^{2}\right) Y \pm \sqrt{\left[-4 d_{1 i}^{2} S_{i}^{2}\left(S_{i}^{2}-Y^{2}\right)+\left(S_{i}^{2}+d_{1 i}^{2}-\left(X-d_{1 i}\right)^{2}-Y^{2}\right)^{2} S_{i}^{2}\right]}}{2\left(S_{i}^{2}-Y^{2}\right)}, i=1 . . \mathrm{n} \\
& d_{2 i}=\left(x_{t}+X\right)-x_{i}, i=1 . . \mathrm{n} \\
& h_{2 i}=\left(y_{i}+H C_{i}\right)-\left(y_{t}-Y\right), i=1 . . \mathrm{n} \\
& h_{3 i}=h_{1 i}, i=1 . . \mathrm{n} \\
& L_{1 i}=\sqrt{\left(d_{1 i}{ }^{2}+h_{1 i}{ }^{2}\right)}, i=1 . . \mathrm{n} \\
& L_{2 i}=\sqrt{\left(d_{2 i}^{2}+h_{2 i}^{2}\right)}, i=1 . . \mathrm{n} \\
& L_{3 i}=L_{1 i}, i=1 . . \mathrm{n} \\
& \text { feclr }_{i}=\text { feclr }_{\text {min }} i=1 . . \mathrm{n} \\
& \beta_{i}=\sin ^{-1}\left\{\left[f e c l r_{i} \cos \left(\varphi_{i}\right) / L L\right]\right\}, i=1 \ldots \mathrm{n} \\
& \alpha_{i}=\tan ^{-1}\left\{\frac{L L}{\varepsilon}\left[\tan \left(\varphi_{i}+\beta_{i}\right)+\frac{D}{L L}\right]+\underset{i=1 \ldots \mathrm{n}}{\left.+\left[\frac{L L}{\varepsilon}-\frac{D}{\varepsilon} \tan \left(\varphi_{i}+\beta_{i}\right)-1\right]\left[\frac{\cos \varphi_{i}-\mu \sin \varphi_{i}}{\sin \varphi_{i}+\mu \cos \varphi_{i}}\right]\right\},},\right. \\
& H C_{i}=\frac{L C_{i} \sin \left(\alpha_{i}-\varphi_{i}\right)+L L \sin \beta_{i}+D \cos \beta_{i}}{\cos \varphi_{i}}+C D, i=1 \ldots \mathrm{n} \\
& H_{1 i}=\frac{T_{1} d_{1 i}}{L_{1 i}} \sqrt{1-\left[\frac{w_{1} d_{1 i}}{2 T_{1}}\right]^{2}}-\frac{w_{1} h_{1 i} d_{1 i}}{2 L_{1 i}}, i=1 \ldots n
\end{aligned}
$$




$$
\begin{gathered}
V_{1 c i}=\frac{H_{1 i} h_{1 i}}{d_{1 i}}-\frac{R_{1 i}}{2}, i=1 \ldots n \\
T_{2 c i}=\sqrt{\left(V_{1 c i}{ }^{2}+H_{1 i}{ }^{2}\right)}, i=1 \ldots \mathrm{n} \\
H_{2 i}=\frac{T_{2 c i} d_{2 i}}{L_{2 i}} \sqrt{1-\left[\frac{w_{2} d_{2 i}}{2 T_{2 c i}}\right]^{2}}-\frac{w_{2} h_{2 i} d_{2 i}}{2 L_{2 i}}, i=1 \ldots n \\
V_{2 c i}=\frac{H_{2 i} h_{2 i}}{d_{2 i}}-\frac{R_{2 i}}{2}, i=1 \ldots n \\
H_{3 i}=\frac{\tan \alpha_{i}\left(H_{1 i}-H_{2 i}\right)-\left(V_{1 c i}+V_{2 c i}-W_{C}\right)+\frac{w_{3} L_{3 i}}{2}}{\frac{h_{3 i}}{d_{3 i}-\tan \alpha_{i}}}, i=1 \ldots \mathrm{n} \\
V_{3 c i}=\frac{H_{3 i} h_{3 i}}{d_{3 i}}-\frac{R_{3 i}}{2}, i=1 \ldots \mathrm{n} \\
T_{1 m a x} \geq T_{1 i}, i=1 \ldots \mathrm{n} \\
T_{3 m a x}>=\sqrt{\left[V_{3 c i}+R_{3 i}\right]^{2}+\left[H_{3 i}\right]^{2}}, i=1 \ldots \mathrm{n} \\
T_{i} \sin \alpha=V_{1 c i}+V_{2 c i}+V_{3 c i}-W_{C}, i=1 \ldots \mathrm{n} \\
T_{i} \cos \alpha_{i}=H_{1 i}+H_{3 i}-H_{2 i}, i=1 \ldots \mathrm{n} \\
N_{i}=\frac{T_{i} \cos \alpha_{i}}{\left(\sin \varphi_{i}+\mu \cos \varphi_{i}\right)}, i=1 \ldots \mathrm{n} \\
W_{i}=T_{i} \sin \alpha_{i}+N_{i} \cos \varphi_{i}-\mu N_{i} \sin \varphi_{i}, i=1 \ldots \mathrm{n}
\end{gathered}
$$

Definitions:

$\mathrm{n}=$ number of terrain points (TP) within yarding limits

$\mathrm{W}_{\mathrm{i}}=$ maximum log load that can be carried from $\mathrm{TP}_{\mathrm{i}}$ to the landing, $\mathrm{kN}$

$\mathrm{W}_{\mathrm{C}}=$ weight of carriage, $\mathrm{kN}$

$\mathrm{S}_{\mathrm{i}}=$ stretched skyline length between yarder headspar and tailspar or anchor when carriage is at $\mathrm{TP}_{\mathrm{i}}, \mathrm{m}$

$\mathrm{X}=$ horizontal distance between headspar and tailspar or anchor, $\mathrm{m}$

$\mathrm{Y}=$ vertical distance between headspar and tailspar or anchor, $\mathrm{m}$

$\mathrm{x}_{\mathrm{i}}=$ horizontal coordinate of $\mathrm{TP}_{\mathrm{i}}, \mathrm{m}$

$\mathrm{y}_{\mathrm{i}}=$ vertical coordinate of $\mathrm{TP}_{\mathrm{i}}, \mathrm{m}$

$\mathrm{x}_{\mathrm{t}}=$ horizontal coordinate of headspar, $\mathrm{m}$

$\mathrm{y}_{\mathrm{t}}=$ vertical coordinate of top of headspar, $\mathrm{m}$

$\mathrm{L}_{1 \mathrm{i}}=$ stretched skyline length between carriage at $\mathrm{TP}_{\mathrm{i}}$ and top of the headspar when carriage is at $\mathrm{TP}_{\mathrm{i}}, \mathrm{m}$

$\mathrm{L}_{2 \mathrm{i}}=$ stretched skyline length between carriage at $\mathrm{TP}_{\mathrm{i}}$ and top of the tailspar when carriage is at $\mathrm{TP}_{\mathrm{i}}, \mathrm{m}$

$\mathrm{L}_{3 \mathrm{i}}=$ mainline length between the carriage at $\mathrm{TP}_{\mathrm{i}}$ and top of the headspar when carriage is at $\mathrm{TP}_{\mathrm{i}}, \mathrm{m}$

$\mathrm{d}_{\mathrm{ki}}=$ horizontal projection of cable segment $\mathrm{k}(\mathrm{k}=1,2,3)$ for carriage at $\mathrm{TP}_{\mathrm{i}}, \mathrm{m}$

$\mathrm{h}_{\mathrm{ki}}=$ vertical projection of cable segment $\mathrm{k}(\mathrm{k}=1,2,3)$ for carriage at $T P_{\mathrm{i}}, \mathrm{m}$

$\mathrm{w}_{\mathrm{i}}=$ unit weight of cable segment $\mathrm{k}(\mathrm{k}=1,2,3)$ for carriage at $\mathrm{TP}_{\mathrm{i}}, \mathrm{kN} / \mathrm{m}$

$\mathrm{R}_{\mathrm{ki}}=$ segment weights $(\mathrm{k}=1,2,3)$ for carriage at $\mathrm{TP}_{\mathrm{i}}, \mathrm{kN}$

$\mathrm{V}_{\mathrm{kci}}=$ vertical force component for segment $\mathrm{k}(\mathrm{k}=1,2,3)$ at carriage for carriage at $\mathrm{TP}_{\mathrm{i}}, \mathrm{kN}$

$\mathrm{H}_{\mathrm{ki}}=$ horizontal force component of segment $\mathrm{k}(\mathrm{k}=1,2,3)$ at $\mathrm{TP}_{\mathrm{i}}, \mathrm{kN}$

$\mathrm{HC}_{\mathrm{i}}=$ vertical distance to skyline above $\mathrm{TP}_{\mathrm{i}}, \mathrm{m}$

$\mathrm{LC}_{\mathrm{i}}=$ tagline length when carriage is at $\mathrm{TP}_{\mathrm{i}}, \mathrm{m}$

$\mathrm{CD}=$ carriage depth, $\mathrm{m}$

$\mathrm{T}_{1 \max }=$ allowable skyline tension at headspar, $\mathrm{kN}$

$\mathrm{T}_{3 \max }=$ allowable mainline tension at headspar, $\mathrm{kN}$ 
$\mathrm{T}_{1 \mathrm{i}}=$ tension in skyline at headspar when carriage is at $\mathrm{TP}_{\mathrm{i}}, \mathrm{kN}$

$\mathrm{T}_{2 \mathrm{ci}}=$ tension in skyline at carriage when carriage is at $\mathrm{TP}_{\mathrm{i}}, \mathrm{kN}$

$\mathrm{T}_{\mathrm{i}}=$ tagline tension when carriage is at $T P_{\mathrm{i}}, \mathrm{kN}$

$\alpha_{i}=$ angle of tagline, when carriage is at $\mathrm{TP}_{\mathrm{i}}$, degrees

$\beta_{i}=\log$ to ground angle when carriage is at $\mathrm{TP}_{\mathrm{i}}$, degrees

$\varphi_{\mathrm{i}}=$ ground slope below end of $\log$ when carriage is $\mathrm{TP}_{\mathrm{i}}$, degrees

feclr $_{i}=$ front end log vertical clearance when carriage is at $\mathrm{TP}_{\mathrm{i}}, \mathrm{m}$

$\mathrm{feclr}_{\min }=$ minimum permissible front end log clearance, $\mathrm{m}$

$\mathrm{HC}_{\mathrm{i}}=$ vertical distance from terrain point $\mathrm{i}$ to skyline when carriage is above $\mathrm{TP}_{\mathrm{i}}, \mathrm{m}$

$\mathrm{N}_{\mathrm{i}}=$ normal force of $\log$ on ground when carriage is at $\mathrm{TP}_{\mathrm{i}}, \mathrm{kN}$

$u=$ coefficient of $\log$ to ground friction, $\mathrm{kN} / \mathrm{kN}$

$\mathrm{D}=$ average log diameter, or equivalent log diameter for multiple logs, $\mathrm{m}$

$\mathrm{LL}=$ length of $\log , \mathrm{m}$

$\varepsilon=$ distance from front of $\log$ to center of mass of $\log$, assumed $=\mathrm{LL} / 2, \mathrm{~m}$

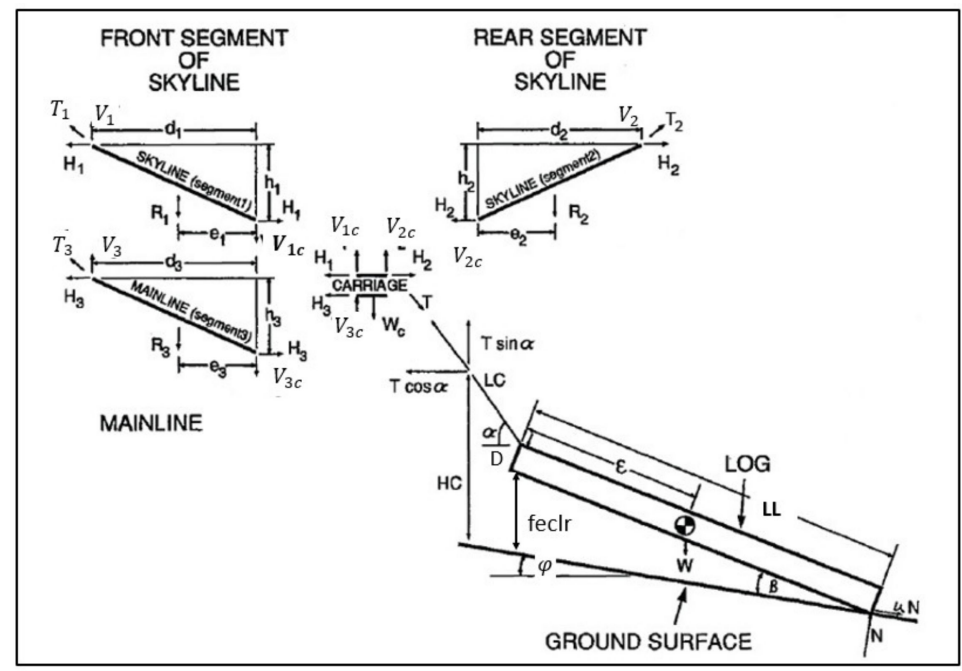

Figure 4. Nomenclature for the segments of the standing skyline and the partially suspended log (adapted from [1]). The tagline length, LC, is the segment length from the attachment point of the choker to the bottom of the carriage.

\subsection{Solution Method}

In the following, the payload analysis software defines the distance between the carriage and the logs as the tagline length, this distance is the sum of the tagline as defined in Figure 1, and the chokers. Because of the nonlinear constraints we use heuristic methods to solve for the maximum log load that can be brought to the landing from each point within the yarding limits using four steps: Step 1. Identify the stretched skyline length that provides the minimum front-end log clearance at the critical terrain point using the minimum acceptable tagline length. The minimum tagline length is theoretically zero, but practically considers the choker length, toggle, or butt plate below the carriage. The minimum front-end log clearance is used because this allows the ground to support as much of the log weight as possible as opposed to the skyline. This is done by finding the stretched line length at each terrain point within the yarding limits and selecting the shortest of those.

Step 2. Using the shortest stretched line length identified in Step 1, calculate the vertical carriage clearance, $\mathrm{HC}$ at each terrain point within yarding limits using the minimum permissible front end log clearance. We suggest identifying the vertical carriage clearance and the variable tagline length, LC, simultaneously rather than using Equations (7) and (17) simultaneously. An iterative search, such as the secant method [17] closes quickly on the required values of HC and LC within a couple of iterations. The procedure involves two guesses on the variable tagline length followed by calculation of the skyline 
length associated with the two tagline guesses. Iteration continues until the skyline length associated with the variable length tagline closes within an acceptable tolerance.

Step 3. Using the maximum allowable skyline tension, calculate the maximum log load that can be carried at each point within yarding limits.

Step 4. At each terrain point, identify the minimum of the log loads identified from Step 3 from the terrain point to the log landing. For each terrain point, this will identify the maximum log load that can be transported from that terrain point to the landing.

\section{Example and Results}

The following example shows the difference between a standing skyline with a fixed length tagline and a skyline with a variable length tagline. Table 1 shows the basic yarder and $\log$ parameters.

Table 1. Input parameters for standing skyline.

\begin{tabular}{cc}
\hline Tower Height & $21.9 \mathrm{~m}$ \\
Tailspar Height & $0 \mathrm{~m}$ \\
Skyline & $226.9 \mathrm{kN}$ maximum tension, $45.1 \mathrm{~N} / \mathrm{m}$ \\
Mainline & $140.9 \mathrm{kN}$ maximum tension, $27.3 \mathrm{~N} / \mathrm{m}$ \\
Carriage Weight & $10.2 \mathrm{kN}$ \\
Carriage Depth & $0 \mathrm{~m}$ \\
Log Length & $12.2 \mathrm{~m}$ \\
Distance to Center of Mass of Logs & $6.1 \mathrm{~m}$ \\
Average Equivalent Diameter of Logs & $0.9 \mathrm{~m}$ \\
Average Log to Ground Friction & 0.9 \\
Outer Yarding Limit & Terrain Point 33 \\
\hline
\end{tabular}

The carriage position at each terrain point is shown in Figure 5. For the variable tagline scenario, the tagline varied from a minimum of $2.1 \mathrm{~m}$ at terrain point 6 to a maximum of $53.8 \mathrm{~m}$ at terrain point 25. In Tables 2 and 3, the Log Load at Point identifies the largest $\log$ load that could be picked up at the terrain point. The Log Load to Landing identifies the largest log load that could be transported from each terrain point to the landing. In other words, the largest load that can be transported to the landing is the minimum of the largest $\log$ loads at points between a terrain pickup point and the landing (Equation (3)). For example, if a fixed length tagline is used, the maximum load that can be picked up at terrain point 15 and brought to the landing is about $58 \mathrm{kN}$. If a variable length tagline is used, the maximum log load that can be carried from terrain point 15 to the landing is about $89 \mathrm{kN}$, an increase of about 53 percent. The maximum variable tagline scenario $\log$ loads near the landing appear lower than the fixed length tagline scenario. This is an artifact of the solution method which assumes the skyline is the limiting line tension. Near the landing, the mainline was limiting. Since the longer tagline shifts more of the log load to the ground, the increased normal force on the ground creates more log drag. Increased $\log$ drag increases the mainline tension. Increased mainline tension requires a reduction in $\log$ load to stay under the maximum mainline tension. This is usually not an issue, since the extremely large log loads near the tower are not realized in practice. If it were an issue, then the variable tagline length would be reduced in length to the fixed tagline length for loads picked up near the landing. If full suspension had been required over the lower back end, such as terrain points 24 to 33 , the tagline would have been shortened to provide full suspension. In that case, the maximum log load that could be yarded to the landing for logs picked up between terrain points 24 to 33 would be the same for both methods. For logs picked up between 5 and 23 the log loads would differ as shown in Figure 6. 


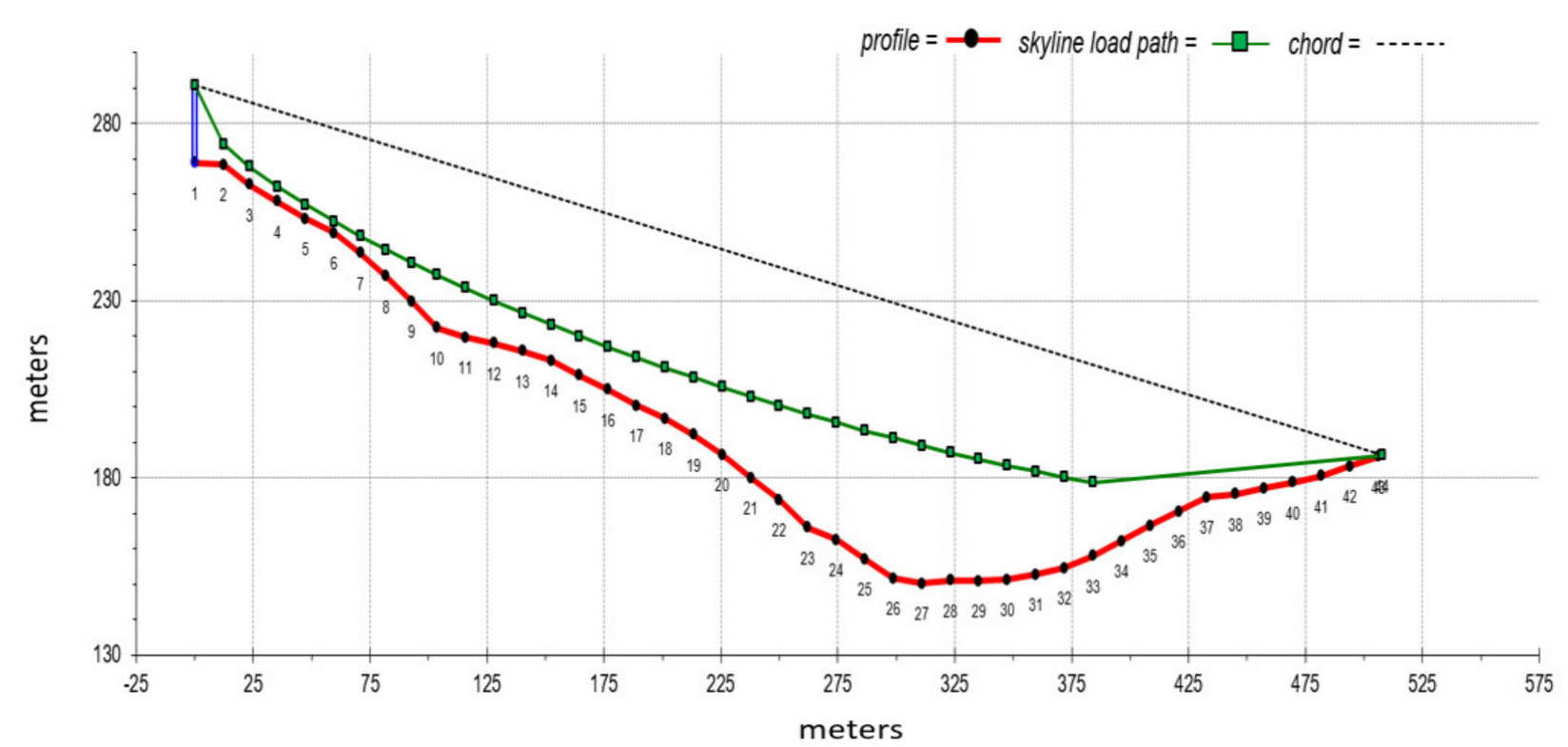

Figure 5. Example profile showing carriage position along the standing skyline. The outer yarding limit is at terrain point 33.

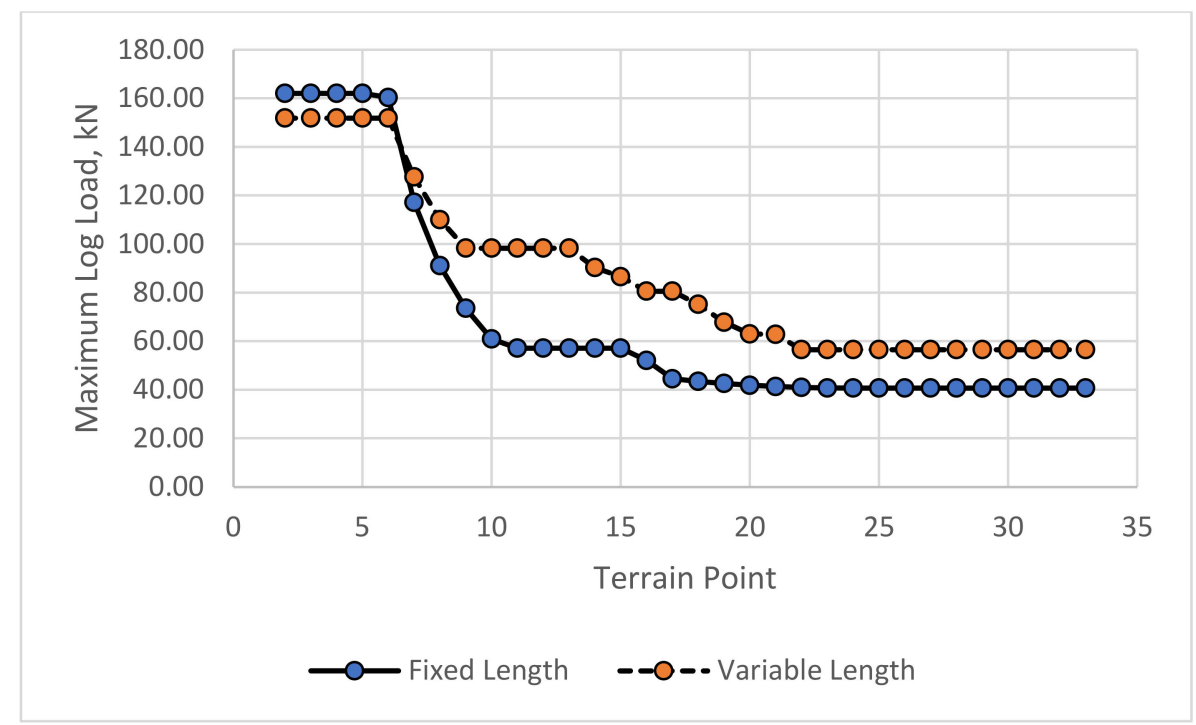

Figure 6. The maximum load that can be picked up at a terrain point and yarded to the landing for the fixed length and variable length tagline scenarios.

\section{Discussion}

We refer to the maximum log load identified in Step 4 as a tight lower bound on the maximum log load. We use the term tight lower bound, because it is possible, in some cases, to carry even a larger log load by including the effects of skyline stretch [2]. In the algorithm presented, we have assumed the skyline is stretched to its maximum allowable tension as the carriage comes up the skyline. To the extent that the skyline tension is not at its maximum allowable tension, the stretched skyline will be a little shorter and the front-end log clearance will be a little higher, implying we could add a little more log load. However, given the accuracy of the profile, the spring constants of the guylines and stumps, and the imprecise knowledge of the wire rope properties (e.g., modulus of elasticity of the wire rope), our assumptions here are conservative. If the user desires to include skyline stretch in the calculation, the iterative procedure used in Step 2 is extended to include a feedback loop between skyline stretch and skyline tension using the procedure such as 
presented in [1]. They used an average tension in a cable segment and Hooke's Law to estimate the un-stretched cable length, where [18] demonstrated that the average tension was a suitable surrogate for a tension function that is a function of position along the cable when considering elongation to be a result of elastic stretch.

Tables 2 and 3 present the modeling results for the fixed and variable length tagline systems. Up to terrain point 5 it can be seen that the mainline is limiting the maximum log load for both systems. For terrain points 1 to 5 the maximum log load is greater when using the fixed tagline length system due to more equal sharing of the load between the skyline and the mainline. Beyond terrain point 6 the skyline tension becomes limiting and it can be seen that the variable length tagline system improves load sharing between the skyline and the mainline resulting in increased maximum log loads. When using the fixed tagline length system, the mainline tension is dramatically reduced when the turn is suspended (i.e., terrain points 17 to 33 ) and the skyline must provide most of the lifting force. When the turn is partially suspended at the same terrain points (17 to 33) using the variable tagline length system the mainline tension increases due to friction between the logs and the ground, and due to the angle of the mainline this increases the vertical component of the tension which creates more lift from the mainline. During partial suspension the increased lift due the mainline is combined with part of the weight of the load being supported by the ground to dramatically increase the maximum log load. It should be noted that these results are a function of the uphill yarding configuration, where the mainline can contribute to the lifting force acting on the carriage.

Table 2. Example standing skyline analysis with fixed tagline length. The tagline length is the length between the point of choker attachment and the bottom of the carriage.

\begin{tabular}{|c|c|c|c|c|c|c|c|}
\hline Terrain & Skyline & Mainline & Log Load & Log Load & Skyline & Front End & Tagline \\
\hline Point & $\begin{array}{c}\text { Tension } \\
(\mathrm{kN})\end{array}$ & $\begin{array}{l}\text { Tension } \\
(\mathrm{kN})\end{array}$ & $\begin{array}{l}\text { at Point } \\
(\mathrm{kN})\end{array}$ & $\begin{array}{l}\text { to Landing } \\
(\mathrm{kN})\end{array}$ & $\begin{array}{c}\text { Clearance } \\
\text { (m) }\end{array}$ & $\begin{array}{c}\text { Log Clearance } \\
(\mathrm{m})\end{array}$ & $\begin{array}{l}\text { Length } \\
\text { (m) }\end{array}$ \\
\hline 2 & 58.4 & 140.9 & 162.0 & 162.0 & 6.1 & 3.6 & 2.1 \\
\hline 3 & 113.8 & 140.9 & 178.7 & 162.0 & 5.7 & 3.2 & 2.1 \\
\hline 4 & 161.6 & 140.9 & 182.7 & 162.0 & 4.8 & 2.4 & 2.1 \\
\hline 5 & 199.4 & 140.9 & 192.9 & 162.0 & 4.7 & 2.2 & 2.1 \\
\hline 6 & 226.9 & 123.2 & 160.3 & 160.3 & 3.9 & 1.5 & 2.1 \\
\hline 7 & 226.9 & 84.4 & 117.1 & 117.1 & 5.5 & 3.0 & 2.1 \\
\hline 8 & 226.9 & 57.5 & 91.1 & 91.1 & 8.3 & 5.6 & 2.1 \\
\hline 9 & 226.9 & 38.0 & 73.5 & 73.5 & 11.8 & 9.1 & 2.1 \\
\hline 10 & 226.9 & 23.5 & 60.9 & 60.9 & 15.8 & \multicolumn{2}{|c|}{ Full Suspension } \\
\hline 11 & 226.9 & 21.6 & 57.1 & 57.1 & 14.8 & \multicolumn{2}{|c|}{ Full Suspension } \\
\hline 12 & 226.9 & 31.9 & 67.6 & 57.1 & 13.0 & 10.4 & 2.1 \\
\hline 13 & 226.9 & 34.5 & 68.3 & 57.1 & 11.7 & 9.1 & 2.1 \\
\hline 14 & 226.9 & 32.7 & 63.0 & 57.1 & 11.0 & 8.4 & 2.1 \\
\hline 15 & 226.9 & 28.0 & 57.7 & 57.1 & 12.0 & 9.4 & 2.1 \\
\hline 16 & 226.9 & 23.0 & 52.1 & 52.1 & 13.1 & 10.5 & 2.1 \\
\hline 17 & 226.9 & 15.2 & 44.5 & 44.5 & 14.6 & \multicolumn{2}{|c|}{ Full Suspension } \\
\hline 18 & 226.9 & 14.6 & 43.5 & 43.5 & 15.4 & \multicolumn{2}{|c|}{ Full Suspension } \\
\hline 19 & 226.9 & 14.0 & 42.6 & 42.6 & 17.0 & \multicolumn{2}{|c|}{ Full Suspension } \\
\hline 20 & 226.9 & 13.5 & 41.9 & 41.9 & 20.0 & \multicolumn{2}{|c|}{ Full Suspension } \\
\hline 21 & 226.9 & 13.1 & 41.3 & 41.3 & 23.8 & \multicolumn{2}{|c|}{ Full Suspension } \\
\hline 22 & 226.9 & 12.7 & 41.0 & 41.0 & 27.5 & \multicolumn{2}{|c|}{ Full Suspension } \\
\hline 23 & 226.9 & 12.4 & 40.7 & 40.7 & 33.0 & \multicolumn{2}{|c|}{ Full Suspension } \\
\hline 24 & 226.9 & 12.1 & 40.7 & 40.7 & 34.1 & \multicolumn{2}{|c|}{ Full Suspension } \\
\hline 25 & 226.9 & 11.8 & 40.8 & 40.7 & 37.1 & \multicolumn{2}{|c|}{ Full Suspension } \\
\hline 26 & 226.9 & 11.5 & 41.0 & 40.7 & 40.4 & \multicolumn{2}{|c|}{ Full Suspension } \\
\hline 27 & 226.9 & 11.3 & 41.5 & 40.7 & 39.7 & \multicolumn{2}{|c|}{ Full Suspension } \\
\hline 28 & 226.9 & 11.0 & 42.1 & 40.7 & 36.9 & \multicolumn{2}{|c|}{ Full Suspension } \\
\hline
\end{tabular}


Table 2. Cont

\begin{tabular}{|c|c|c|c|c|c|c|}
\hline Terrain & Skyline & Mainline & Log Load & Log Load & Skyline & Front End \\
\hline 29 & 226.9 & 10.8 & 42.9 & 40.7 & 35.1 & Full Suspension \\
\hline 30 & 226.9 & 10.5 & 44.0 & 40.7 & 33.0 & Full Suspension \\
\hline 31 & 226.9 & 10.2 & 45.3 & 40.7 & 29.8 & Full Suspension \\
\hline 32 & 226.9 & 9.9 & 46.9 & 40.7 & 26.5 & Full Suspension \\
\hline 33 & 226.9 & 9.6 & 48.9 & 40.7 & 21.5 & Full Suspension \\
\hline
\end{tabular}

Table 3. Example skyline analysis with variable tagline length. The tagline length is the length between the point of choker attachment and the bottom of the carriage.

\begin{tabular}{|c|c|c|c|c|c|c|c|}
\hline Terrain & Skyline & Mainline & Log Load & Log Load & Skyline & Front End & Tagline \\
\hline Point & $\begin{array}{c}\text { Tension } \\
(\mathrm{kN})\end{array}$ & $\begin{array}{l}\text { Tension } \\
(\mathrm{kN})\end{array}$ & $\begin{array}{l}\text { at Point } \\
(\mathrm{kN})\end{array}$ & $\begin{array}{l}\text { to Landing } \\
(\mathrm{kN})\end{array}$ & $\begin{array}{l}\text { Clearance } \\
(\mathrm{m})\end{array}$ & $\begin{array}{c}\text { Log Clearance } \\
(\mathrm{m})\end{array}$ & $\begin{array}{l}\text { Length } \\
\text { (m) }\end{array}$ \\
\hline 2 & 33.2 & 140.9 & 151.8 & 151.8 & 6.1 & 1.5 & 5.7 \\
\hline 3 & 85.0 & 140.9 & 169.3 & 151.8 & 5.7 & 1.5 & 4.8 \\
\hline 4 & 142.3 & 140.9 & 176.9 & 151.8 & 4.8 & 1.5 & 3.5 \\
\hline 5 & 180.2 & 140.9 & 188.0 & 151.8 & 4.7 & 1.5 & 3.3 \\
\hline 6 & 226.9 & 123.2 & 160.3 & 151.8 & 3.9 & 1.5 & 2.1 \\
\hline 7 & 226.9 & 97.9 & 127.6 & 127.6 & 5.4 & 1.5 & 4.7 \\
\hline 8 & 226.9 & 83.7 & 110.0 & 110.0 & 8.3 & 1.5 & 9.4 \\
\hline 9 & 226.9 & 74.1 & 98.3 & 98.3 & 11.8 & 1.5 & 15.3 \\
\hline 10 & 226.9 & 90.2 & 133.5 & 98.3 & 15.8 & 1.5 & 18.6 \\
\hline 11 & 226.9 & 84.6 & 132.4 & 98.3 & 14.8 & 1.5 & 16.4 \\
\hline 12 & 226.9 & 77.4 & 119.3 & 98.3 & 13.0 & 1.5 & 14.3 \\
\hline 13 & 226.9 & 70.9 & 107.2 & 98.3 & 11.7 & 1.5 & 12.8 \\
\hline 14 & 226.9 & 62.6 & 90.3 & 90.3 & 11.0 & 1.5 & 12.7 \\
\hline 15 & 226.9 & 59.6 & 86.6 & 86.6 & 12.0 & 1.5 & 14.2 \\
\hline 16 & 226.9 & 55.7 & 80.6 & 80.6 & 13.1 & 1.5 & 15.9 \\
\hline 17 & 226.9 & 55.4 & 82.4 & 80.6 & 14.6 & 1.5 & 17.6 \\
\hline 18 & 226.9 & 51.4 & 75.1 & 75.1 & 15.3 & 1.5 & 19.3 \\
\hline 19 & 226.9 & 47.0 & 67.8 & 67.8 & 17.0 & 1.5 & 22.7 \\
\hline 20 & 226.9 & 43.8 & 63.0 & 63.0 & 19.9 & 1.5 & 27.8 \\
\hline 21 & 226.9 & 43.3 & 62.8 & 62.8 & 23.8 & 1.5 & 33.7 \\
\hline 22 & 226.9 & 38.8 & 56.5 & 56.5 & 27.5 & 1.5 & 41.1 \\
\hline 23 & 226.9 & 47.1 & 73.2 & 56.5 & 33.0 & 1.5 & 44.0 \\
\hline 24 & 226.9 & 42.8 & 64.3 & 56.5 & 34.1 & 1.5 & 48.8 \\
\hline 25 & 226.9 & 41.9 & 63.3 & 56.5 & 37.1 & 1.5 & 53.8 \\
\hline 26 & 226.9 & 48.3 & 84.2 & 56.5 & 40.4 & 1.5 & 49.5 \\
\hline 27 & 226.9 & 46.8 & 96.5 & 56.5 & 39.7 & 1.5 & 42.6 \\
\hline 28 & 226.9 & 48.0 & 92.5 & 56.5 & 36.9 & 1.5 & 41.9 \\
\hline 29 & 226.9 & 47.7 & 96.3 & 56.5 & 35.1 & 1.5 & 38.7 \\
\hline 30 & 226.9 & 45.5 & 104.0 & 56.5 & 33.0 & 1.5 & 33.5 \\
\hline 31 & 226.9 & 45.4 & 107.3 & 56.5 & 29.8 & 1.5 & 29.6 \\
\hline 32 & 226.9 & 38.6 & 114.3 & 56.5 & 26.5 & 1.5 & 23.5 \\
\hline 33 & 226.9 & 35.4 & 118.4 & 56.5 & 21.5 & 1.5 & 18.0 \\
\hline
\end{tabular}

Some yarders are able to change the length of the standing skyline once or twice as the load is being brought in. This configuration is often referred to as a Live Skyline with Lifts and Drops, but is actually a series of standing skylines. Usually, the carriage is halted and the skyline raised or lowered before carriage inhaul is resumed. A fixed length tagline is used in these operations as well. The standing skyline with variable tagline presents an alternative operating method. A hybrid of the two approaches is also possible. The methodology we have presented can be used for operational harvest planning. However, we see even greater benefits in real-time forest operations. Several available carriages have the ability to change the tagline length as the carriage is pulled to the landing by the mainline. For those carriages, the tagline length is manually shortened by the rigging crew 
by radio signals. The crew is limited in that they have other work to perform. The crew will generally shorten the tagline once or twice as the carriage heads up the hill. With smart carriage technology, the line could be handled by the carriage giving maximum log load and freeing up the rigging crew.

\section{Conclusions}

Due to the large potential improvement in log load capacity using variable length taglines, we expect the smart carriage technology will expand the use of the variable length taglines in standing skyline carriages. In addition to manual control from the field, potential approaches include (1) laser range finders on carriages and (2) GPS coupled with high quality LiDAR-derived mapping. Much of the yarding on steep slopes is now done using tree lengths, as opposed to log lengths. Trees are felled mechanically and bunched. The yarding is done using grapples to secure the logs rather than chokers. Little work, theoretically or empirically, has been done to model either the use of grapples or full tree yarding forces on steep slopes. Future work in these areas would improve performance estimates. We have modeled a three segment standing skyline system suitable for uphill logging in terrain where a haulback line is not required. The formulation can be extended by adding a fourth line segment if a haulback line is required for either yarding across flat areas, across a valley, or for downhill yarding. Although several researchers have compared calculated (predicted) and empirical observations of cable tensions and log loads for the standing skyline using the model formulations in this manuscript, none have evaluated the variable tagline. Future work should include empirical observations as well as case studies using the variable tagline to develop the business model that may spur equipment development and wider adoption.

Author Contributions: Conceptualization, J.S. and J.W.; methodology, J.S. and K.L.; software, J.S.; validation, J.S. and K.L.; formal analysis, J.S. and K.L.; writing-original draft preparation, J.S., K.L. and J.W.; writing-review and editing, J.S., K.L. and J.W. All authors have read and agreed to the published version of the manuscript.

Funding: This research received no external funding.

Conflicts of Interest: The authors declare no conflict of interest.

\section{References}

1. Kendrick, D.; Sessions, J. A solution procedure for calculating the standing skyline load path for partial and full suspensions. For. Prod. J. 1991, 41, 57-60.

2. Brown, C.; Sessions, J. A maximum load path solution for the standing skyline. For. Sci. 1996, 42, $220-227$.

3. Bont, L.; Heinimann, H.R. Optimum geometric layout of a single cable road. Eur. J. For. Res. 2012, 131, 1439-1448. [CrossRef]

4. Dupire, S.; Bourrier, F.; Berger, F. Predicting load path and tensile forces during cable yarding operations on steep terrain. J. For. Res. 2016, 21, 1-14. [CrossRef]

5. Knobloch, C.; Bont, L.G. A New Method to Compute Mechanical Properties of a Cable Road Skyline. In Proceedings of the FORMEC 2018. Proceedings of the 51st International Symposium on Forest Mechanization, Madrid, Spain, 24-28 September 2018; pp. 209-211.

6. Dupire, S.; Bourrier, F. CableHelp: A numerical tool to optimize the set-up of a standing skyline and improve cable yarding planning. In Proceedings of the IUFRO World Congress, Salt Lake City, UT, USA, 5-11 October 2014. Available online: https://www.researchgate.net/publication/268514337_CableHelp_A_numerical_tool_to_optimize_the_set-up_of_a_ standing_skyline_and_improve_cable_yarding_planning (accessed on 26 June 2021). 14p.

7. Spinelli, R.; Magagnotti, N.; Cosola, G.; Grigolato, S.; Marchi, L.; Proto, A.; Labelle, E.; Visser, R.; Erber, G. Skyline tension and dynamic loading for cable yarding comparing conventional single-hitch versus horizontal double-hitch suspension carriages. Int. J. For. Eng. 2021, 1-11. [CrossRef]

8. Carson, W. Analysis of Running Skyline with Drag; USDA Forest Service, Research Paper PNW-193; Pacific Northwest Forest and Range Experiment Station: Portland, OR, USA, 1971.

9. Sessions, J.; Leshchinsky, B.; Chung, W.; Boston, K.; Wimer, J. Theoretical Stability and Traction of Steep Slope Tethered Feller-Bunchers. For. Sci. 2017, 63, 192-200. [CrossRef]

10. Carson, W. Determination of Skyline Load Capability with a Programmable Pocket Calculator; USDA Forest Service Res. Paper PNW-205; Pacific Northwest Forest and Range experiment Station: Portland, OR, USA, 1976; 11p. 
11. Falk, G. Predicting the Payload Capability of Cable Logging Systems Including the Effect of Partial Suspension; USDA Forest Service Res. Paper. NE-479; Pacific Northwest Forest and Range experiment Station: Portland, OR, USA, 1981; 29p.

12. Carson, W.; Mann, C. A Technique for the Solution of Skyline Catenary Equations; USDA Forest Service Res. Paper PNW-120; Pacific Northwest Forest and Range experiment Station: Portland, OR, USA, 1970; Volume 11, 9p.

13. Mologni, O.; Marchi, L.; Lyons, C.K.; Grigolato, S.; Cavalli, R.; Röser, D. Skyline Tensile Forces in Cable Logging: Field Observations vs. Software Calculations. Croat. J. For. Eng. 2021, 42, 227-243. [CrossRef]

14. Mologni, O.; Lyons, C.K.; Zambon, G.; Proto, A.; Zimbalatti, G.; Cavalli, R.; Grigolato, S. Skyline tensile force monitoring of mobile tower yarders operating in the Italian Alps. Eur. J. For. Res. 2019, 138, 847-862. [CrossRef]

15. Rheinberger, S.; SkylineXL 18.0. Skyline Profile and Payload Analysis. USFS PNW Forest Products Programs and Software. Available online: https://www.fs.usda.gov/detail/r6/landmanagement/resourcemanagement/?cid=fsbdev2_027048 (accessed on 3 April 2019).

16. Sessions, J. LOGGERPC V. 4.0; Department of Forest Engineering, Oregon State University: Corvallis, OR, USA, 2002.

17. Mathews, J. Numerical Methods for Computer Science, Engineering, and Mathematics; Prentice Hall, Inc.: Hoboken, NJ, USA, 1987; $507 p$.

18. Lyons, C.K. Considering cable stretch in logging applications. Int. J. For. Eng. 2008, 19, 29-35. [CrossRef] 